\title{
Influence of Neuropeptide Y and Neuropeptide Y 2 Receptor Variants in Acute Coronary Syndrome
}

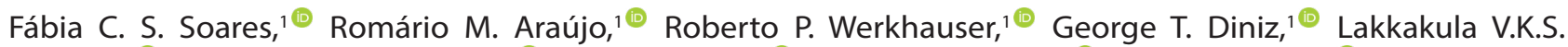

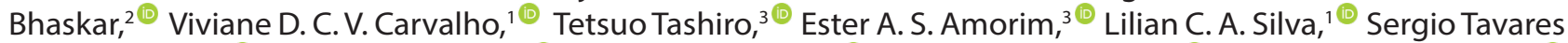
Montenegro, ${ }^{4,5,6}$ Heytor V.P. C. Neco, ${ }^{\circledR \oplus}$ Clarice N. L. Moraes, ${ }^{1 \oplus}$ Danyelly B. G. Martins, ${ }^{3 \oplus}$ Silvia M. L. Montenegro ${ }^{1 \oplus}$ FIOCRUZ - Fundação Oswaldo Cruz - Instituto Aggeu Magalhães,' Recife, PE - Brazil Guru Ghasidas Vishwavidyalaya, ${ }^{2}$ Chhattisgarh - Índia Universidade Federal de Pernambuco, ${ }^{3}$ Recife, PE - Brazil PROCAPE - Pronto Socorro Cardiológico de Pernambuco, ${ }^{4}$ Recife, PE - Brazil Real Hospital de Beneficência Portuguesa de Pernambuco, ${ }^{5}$ Recife, PE - Brazil CECOM - Centro Cardiológico Ovídio Montenegro, ${ }^{6}$ Recife, PE - Brazil

\section{Abstract}

Background: The neuropeptide Y (NPY) is one of the most abundant neurotransmitters in the nervous system. NPY acts as a potent stimulator of angiogenesis, inflammation, and adipogenesis, through the NPY 2 receptor (NPY2R). Changes in the NPY signaling pathway have been linked to Acute Coronary Syndrome (ACS).

Objectives: The purpose of this study is to determine the association between variants in the NPY and NPY2R genes, as well as the severity of acute coronary syndrome (ACS).

Methods: Approximately 221 ACS patients and 278 healthy controls were selected for this study. Four variants in NPY and two variants in NPY2R genes were genotyped using Taqman allelic discrimination and sequencing. The Chi-square and Fisher's exact tests were used to verify the genotype frequencies. The logistic regression analyses were used for the evaluation of the studied variables. Haplotype analysis was used to evaluate the linkage disequilibrium (LD) between the variants $(\mathrm{p}<0.05)$.

Results: An association of NPY c.20T>C variant was found with the ACS group when compared to the healthy group. In the analysis between variants and risk factors in the ACS group, NPY c.84G>A was associated with hypertension. The analysis between TIMI risk showed a significance for NPY c.20T>C between the low and intermediate/high TIMI risk groups. In the haplotype analysis, strong linkage disequilibrium (LD) was found between the variants NPY c.150G>A and NPY c. $-485 T>C$.

Conclusion: The NPY c.20T>C variant appears to contribute to the development of ACS. The NPY2R c.-1116A $>$ G variant may contribute to the early development of ACS and the NPY c.84G $>$ A variant appears to contribute to the development of hypertension. In addition, the NPY c.20T $>$ C is associated with a protective effect in ACS severity.

Keywords: Acute Coronary Syndrome; Neuropeptide Y; Receptors Neuropeptide Y; Nucleotide Polymorphism; Epidemiology.

\section{Introduction}

The neuropeptide $\mathrm{Y}(\mathrm{NPY})$ is a small peptide with 36 amino acids and is one of the most abundant neurotransmitters of the central and peripheral nervous system. ${ }^{1}$ It induces proliferation of vascular smooth muscle cells in humans, promoting the formation and development of new blood vessels. ${ }^{2}$ As a result, current research is focused on developing a drug delivery mechanism for NPY to prolong the therapy of diabetic cardiomyopathy and ischemic heart disease without significant systemic consequences. ${ }^{3}$ In mammals, NPY

Mailing Address: Fábia Soares

Campus da UFPE - Av. Prof. Moraes Rego, s/n. Postal Code: 50670-420, Cidade Universitária, Recife, PE - Brazil.

E-mail: fabiasoares@hotmail.com 
acts through its receptors NPYR1, NPYR2, NPY4R, NPY5R, and NPY6R. The NPY1R, NPY2R, NPY4R, and NPY5R receptors are functional in all mammals, but $Y 6$ is a pseudo-gene in humans and other primates, and is also absent in the mouse genome. ${ }^{4}$ The NPY c.20T>C mutation, which results in the substitution of Leucine for Proline (Leu7Pro) in the pre-pro-NPY signal peptide, is associated with an increase in serum lipid levels. NPY c.20T>C increased the risk of accelerated and early progression of atherosclerosis, ${ }^{5-7}$ acute myocardial infarction and stroke, ${ }^{8}$ coronary artery disease, ${ }^{9}$ hypertension, ${ }^{10,11}$ and obesity in children. ${ }^{12}$ The NPY c.84G>A and c.150G >A variants were investigated for their association with obesity and hypertension, ${ }^{10-11}$ while c.150G>A was studied for its association with atherosclerosis. ${ }^{7}$

By contrast, the NPY c.-485T>C (rs16147) variant, which is located in the promoter region, ${ }^{13}$ has proven to alter NPY expression in vitro, and is likely to affect mRNA expression levels in vivo. ${ }^{14-15}$ Numerous studies have established a link between the c.-485T $>C$ variant and the development of early atherosclerosis ${ }^{7}$ and stroke. ${ }^{16-17}$ Other studies have established a link between this variant and a reduction of insulin resistance and type 2 diabetes. ${ }^{18-19}$ Through the NPY 2 receptor (NPY2R), NPY may also act as a stimulator of angiogenesis, inflammation, and adipogenesis in the abdominal region. ${ }^{20}$ NPY2R variants c. $-1088 \mathrm{C}>\mathrm{T}$ and c. $-1116 \mathrm{~A}>\mathrm{G}$ are associated with obesity, ${ }^{21-24}$ as well as with low HDL-C serum levels. ${ }^{25}$ Since the earliest experimental studies with NPY, its association with cardiovascular diseases has been established, with the evidence that cardiac NPY is released from sympathetic nerves during acute myocardial infarction. ${ }^{26}$ Plasma levels of NPY were found to be high in human suffering from Acute Coronary Syndromes (ACS), such as acute myocardial infarction and during left ventricular failure. ${ }^{27-29} \mathrm{NPY}$ and the NPY2R may serve as biomarkers for ACS prognosis, risk stratification for death or cardiovascular events, or even a potential therapeutic target in other types of treatments. This purpose of this study was to evaluate the influence of NPY and NPY2R variants on the severity of ACS.

\section{Methods}

\section{Population}

The study enrolled patients who were admitted to the Real Heart Hospital (RHH), which is affiliated with the Royal Portuguese Charity Hospital in Pernambuco (RPHCP), located in Recife, Pernambuco, Brazil.
Adult ACS patients $(n=221)$, over 18 years of age, of both sexes, underwent an electrocardiogram, and if necessary, cineangiocardiography was also performed. The myocardial injury markers, creatine kinase-MB (CK$\mathrm{MB})$ and troponin, were measured. Non-ACS patients admitted to the RHH ( $\mathrm{n}=95)$ with atrial fibrillation were also included in this study. The sample size was defined by convenience. A total of 278 healthy blood donors (healthy group), over 18 years of age, of both sexes, were recruited from the Hematology and Hemotherapy Foundation of Pernambuco (Hemope) and participated in interviews on the presence of acute or chronic diseases or significant comorbidities and laboratory tests (HIV, hepatitis C, syphilis, Human T-lymphotropic virus type 1 and 2, and Chagas' disease) to identify infectious parasitic diseases.

\section{Inclusion criteria}

This study enrolled patients who were diagnosed with ACS, after having undergone a physical examination, an electrocardiogram, and a measurement of myocardial injury markers. The non-ACS patients were those hospitalized without a diagnosis of coronary disease and typically who presented atrial fibrillation.

\section{Exclusion Criteria}

Individuals taking anti-inflammatory drugs, those who had suffered a recent trauma, those with a history of active infectious diseases or neoplasms, and those who refused to participate in the study were excluded from the ACS and non-ACS groups.

\section{Ethical considerations}

The Real Heart Hospital/Realcor Research Ethics Committee of the Royal Portuguese Charity Hospital in Pernambuco approved this study (CAAE: 03187512.2.0000.5202). Before sample collection, each subject was informed about the research and signed an informed consent form.

\section{Level of ACS severity in patients}

In all patients, the severity level was determined by the left ventricular ejection fraction, which was determined by the echocardiogram. Additionally, the risk score for Thrombolysis in Myocardial Infarction (TIMI) was used. The TIMI Risk Score is used to categorize patients as having an intermediate and high risk of suffering 
a cardiovascular event. For the patients without the ST-elevation myocardial infarction, seven risk factors were considered. ${ }^{30}$ For the patients with an ST-elevation myocardial infarction (STEMI), eight factors are considered, in accordance with Morrow et al. (2000). ${ }^{31}$

\section{Blood samples and DNA extraction}

During the routine of cardiologic exams performed on RPHCP, peripheral blood samples were collected in a $5 \mathrm{ml}$ EDTA tube to perform molecular analysis at the Oswaldo Cruz Foundation (Fiocruz-PE). Purification of the DNA was carried out according to manufacturer's instructions, using the Illustra blood genomicPrep Mini Spin Kit (GE Healthcare, Buckinghamshire, UK).

\section{Identification and genotyping of variants}

DNA sequencing was used to screen for the NPY gene variants 20T>C (rs16139), c.84G $>\mathrm{A}$ (rs5572), and c.150G $>\mathrm{A}$ (rs5573). Initial denaturation at $95^{\circ} \mathrm{C}$ for 5 minutes was followed by 35 cycles of denaturation $\left(95^{\circ} \mathrm{C}\right.$ for 1 minute), annealing $\left(60^{\circ} \mathrm{C}\right.$ for 30 seconds), and extension $\left(72^{\circ} \mathrm{C}\right.$ for 45 seconds), followed by a final extension at $72^{\circ} \mathrm{C}$ for 7 minutes32. According to manufacturer's recommendations, Platinum ${ }^{\circledR}$ Taq DNA polymerase (Invitrogen Life Technologies) was used. The reagents were used without adding DNA as a negative control. The amplified fragments were viewed on a $1.5 \%$ agarose gel. The PCR products were sequenced and analyzed using the Chromas Lite 2.01 program at the Aggeu Magalhes Institute's Technological Platform Centers (NPT/IAM). The NPY variants c.-485T>C (rs16147) (Assay ID C 2267279 10), NPY2R c.-1088C >T (rs6857715) (Assay ID C 29013142 10), and NPY2R c.-1116A>G (rs6857530) (Assay ID C 44837 30) were identified by applying realtime PCR with Genotyping, which was carried out using the 7500 RealTime PCR System (Applied Biosystems, Foster City, CA, USA) under the following conditions: initial denaturation at $95^{\circ} \mathrm{C}$ for 10 minutes, followed by 40 cycles of denaturation $\left(92^{\circ} \mathrm{C}\right.$ for 15 seconds), annealing $\left(60^{\circ} \mathrm{C}\right.$ for 60 seconds), extension $\left(60^{\circ} \mathrm{C}\right.$ for 60 seconds), and final extension at $60^{\circ} \mathrm{C}$ for 60 seconds.

\section{Statistical analysis}

To determine whether the genotypic frequencies agree with the Hardy-Weinberg proportions, the Chi-square and Fisher's exact tests were used. The clinical variables, inflammatory markers, ischemia, and variants were all evaluated using logistic regression analyses. The data were analyzed using The R Project for Statistical Computing ( $R$ Development Core Team), version 2.10. The haplotype analysis and evaluation of linkage disequilibrium (LD) between variants were performed using the HaploView 4.2 software. When the p-value was less than 0.05 , the data were considered statistically significant.

\section{Results}

\section{Characterization of the study population}

A total of 221 patients with ACS were selected, the majority of whom $(76.02 \%)$ was male. This distribution was also observed for non-ACS patient and health patient groups, comprised of $52.69 \%$ (49/93) female individuals and $84.17 \%$ (234/278) male individuals, respectively. The median age ACS, non-ACS, and healthy patients was respectively $60,6,3$ and 45 years. No significant differences in age were found between the ACS and nonACS groups $(p=0.7775)$, but significant differences were observed between the ACS and the healthy groups $(\mathrm{p}<$ 0.001). According to the TIMI risk, patients with ACS were classified as having a low risk (34.84\%), an intermediate risk $(46.61 \%)$, or a high risk $(18.55 \%)$. Multiple logistic regression analysis revealed that gender, smoking, diabetes, and dyslipidemia are contributing factors to the increased risk of ACS (Supplementary Table S1).

\section{Analysis of the variants}

The groups of patients with ACS and healthy patients showed Hardy-Weinberg equilibrium (HWE) $(p>0.05)$ for all variants in NPY and NPY2R. In the group of non-ACS patients, NPY c.150G $>$ A, NPY2R c. $-1088 C>T$, and c.-1116A $>$ G showed HWE, while NPY c.20T $>C$ and NPY c.84G $>$ A were not in HWE. Therefore, no statistical analyses involved these two populations.

The NPY c.20T $>$ C showed a majority of ancestral homozygous genotype TT (94.57\%) in the ACS group, while $5.43 \%$ of the patients were heterozygous. In the healthy group, $96.40 \%$ of the samples showed the TT genotype, while only $3.60 \%$ presented the TC or CC genotypes. When the analysis after adjusting for age and gender was performed, there was an association between this variant and ACS. Previously, it presented $p=0.3251$ for the TC/CC and $p=0.3307$ for the $C$ allele, later showing a $\mathrm{p}=0.0256$ for the TC/CC and $\mathrm{p}=0.0892$ for the $\mathrm{C}$ allele, with an odds ratio (OR) of approximately three-fold that of the individual having the TC/CC genotype or the C allele to develop ACS, as can be seen in Table 1. 
Int J Cardiovasc Sci. 2021; [online].ahead print, PP.0-0

Soares et al.

Original Article

Influence of NPY and NPY2R variants in ACS

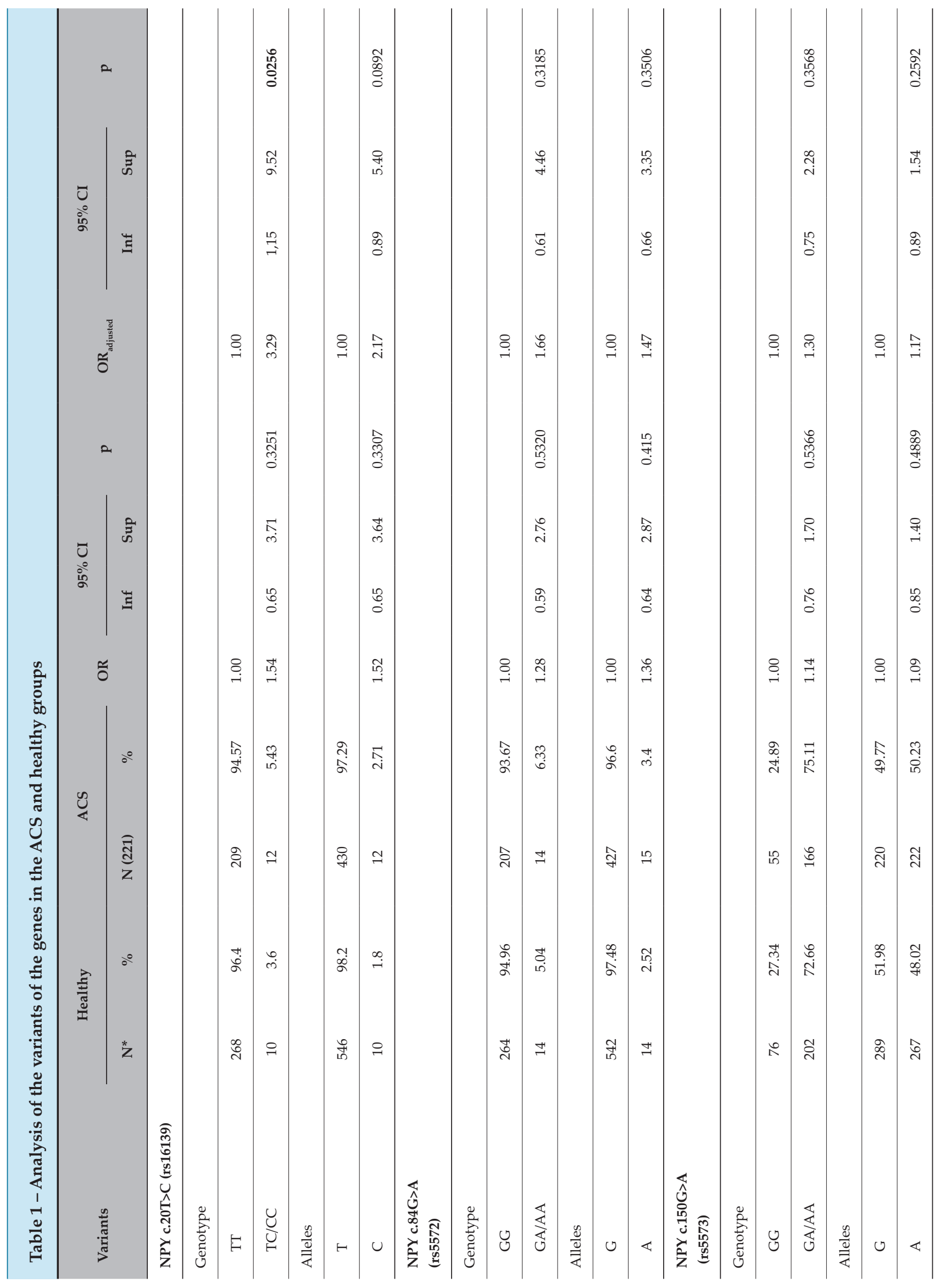




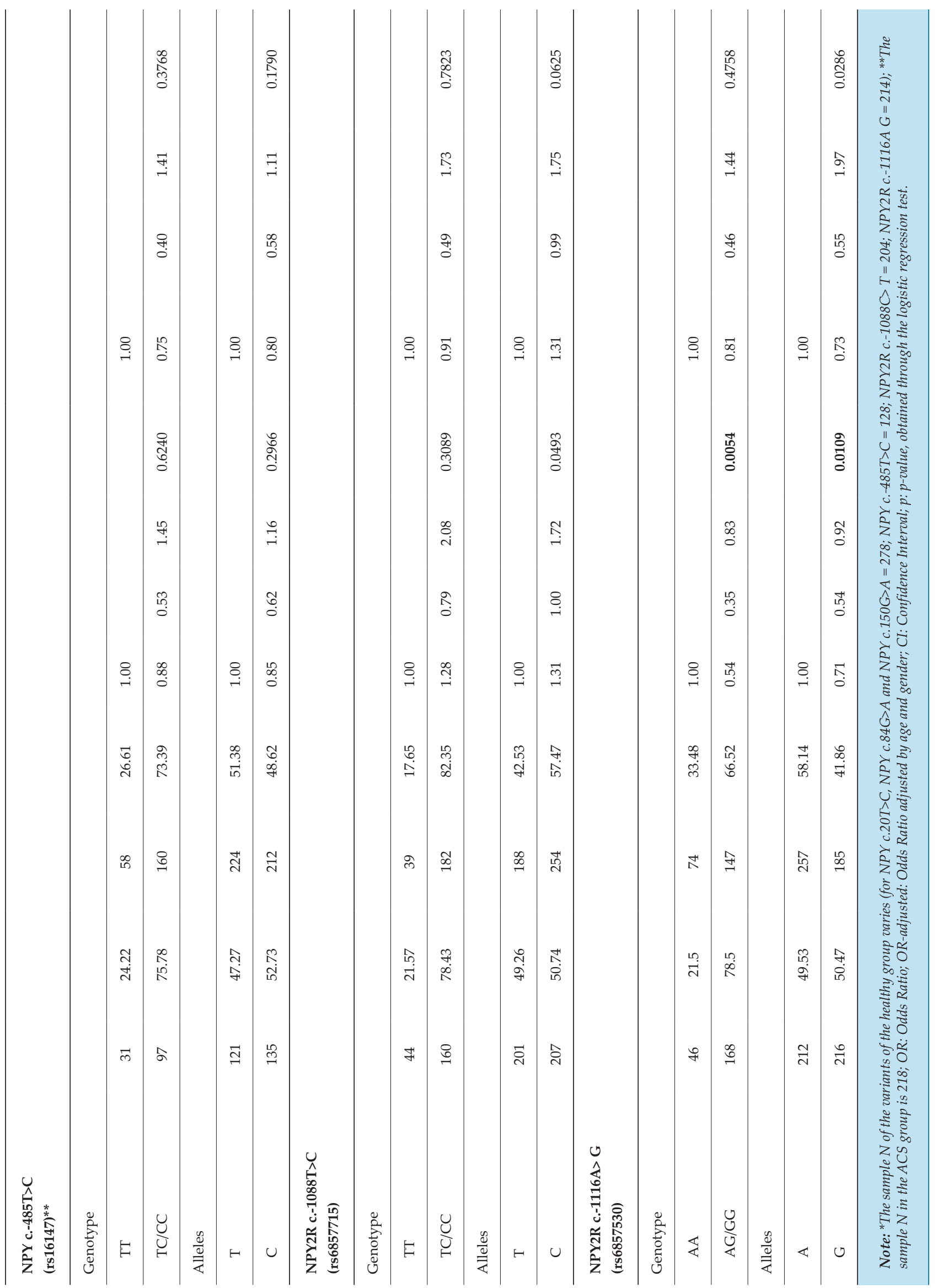


Regarding NPY c.84G>A, the results show that $93.67 \%$ of ACS patients presented the GG genotype, while $6.33 \%$ showed GG or GA genotypes. Results showed that $94.96 \%$ of the samples from healthy individuals presented the GG genotype, while only $5.04 \%$ showed GA or AA genotypes. No statistical difference was found between the groups and no association between NPY c.84G>A and ACS was identified (Table 1).

Results from the NPY c.150G>A showed $24.89 \%$ of the patients with ACS carrying the GG genotype, while $75.11 \%$ of the patients showed GA/AA genotypes. Among the non-ACS patients, $32.97 \%$ showed the GG genotype, while $67.03 \%$ presented the GA/AA genotypes (Supplementary Table S2). The analysis of healthy individuals revealed that the GG genotype was present in $27.34 \%$ of the patients, while $49.28 \%$ presented the GA genotype and $23.38 \%$ the AA genotype (Table 1). No statistical difference was found between the groups and no association between NPY c.150G>A and ACS was identified.

As regards the NPY c. $-485 \mathrm{~T}>\mathrm{C}$ variant, $26.61 \%$ of the ACS group presented the TT genotype, while $73.39 \%$ of these presented the TC/CC genotypes. Among the nonACS patients, $25.81 \%$ presented the TT genotype, while $74.19 \%$ presented the TC/CC. No association was found between this variant and the ACS (Supplementary Table S2). In the healthy group, individuals presented $24.22 \%$ of the TT genotype, while $75.78 \%$ presented the TC/CC genotypes (Table 1). In the two analyses performed with the three populations, no association was found between c. $-485 \mathrm{~T}>\mathrm{C}$ and ACS.

Regarding NPY2R c. $-1088 \mathrm{C}>\mathrm{T}$, the genotypic distribution in the group of patients with ACS showed that $17.65 \%$ presented the TT genotype, while $82.35 \%$ presented the TC/CC genotypes. In the non-ACS patient group, $24.21 \%$ of the individuals showed the TT genotype, while $75.79 \%$ presented TC/CC genotypes (Supplementary Table S2). In the healthy group, only $21.57 \%$ of the individuals showed the TT genotype, while $78.43 \%$ presented the TC/CC genotypes (Table 1 ). In the two analyses performed with the three populations, no association was found between c.-485T>C and ACS.

The results regarding NPY2R c.-1116A $>\mathrm{G}$ showed a genotypic distribution in the ACS group of $33.48 \%$ presenting the CC genotype as compared to $66.52 \%$ presenting the AG/GG genotypes. In the non-ACS group, $26.32 \%$ of the patients showed the AA genotype, while $73.68 \%$ presented the AG/GG genotypes (Supplementary
Table S2). In the healthy group, $21.50 \%$ showed the AA genotype, while $78.50 \%$ presented the AG/GG genotypes. When the logistic regression analysis was performed, an association between c. $-1116 \mathrm{~A}>\mathrm{G}$ and ACS ( $\mathrm{p}=0.0054$ for the AG/GG genotypes and $p=0.0109$ for the $G$ allele) was observed between the healthy and the ACS groups. After adjustment for age and gender, this association continued ( $p=0.4619$ for the AG/GG genotypes and $p=0.2982$ for the $\mathrm{G}$ allele), as can be observed in Table 1 .

\section{Variants versus TIMI risk}

TIMI risk showed an association with the NPY c. $20 \mathrm{~T}>\mathrm{C}$ variant. The NPY c.20T $>\mathrm{C}$ presented a significant difference $(p=0.0261$; OR $=0.25)$ among the low and intermediate/high TIMI risk groups. In the low TIMI risk group, the genotype distribution was $89.61 \%$ TT and $10.39 \%$ TC/CC, while in the intermediate/high TIMI risk group, $97.22 \%$ showed the TT genotype and $2.78 \%$ showed the TC/CC genotypes (Table 2). For the other variants, no association was found with any of the TIMI risk groups.

\section{Relationship between variants and clinical and biological characteristics and habit}

The association of the variants with the following variables of ACS was also analyzed: gender/time, smoking, diabetes, hypertension, dyslipidemia, levels of C-reactive protein (CRP), number of arterial lesions, troponin levels, levels of CK-MB mass, and ejection fraction.

The results showed that in the ACS group, the NPY c. $84 \mathrm{G}>\mathrm{A}$ variant was associated with hypertension, indicating a 3.57-fold chance of developing this disease $(p=0.0223)$ in individuals who do not have GA/AA genotypes (Table 3).

The NPY2R c.-1116A $>G$ variant showed an association with the onset time of ACS (Table 4), indicating that the individual who has this variant has almost twice the chance to developing the early syndrome $(p=0.0253$; $\mathrm{OR}=1.91$ ). However, no association was found for other variants (Supplementary Tables S3, S4, S5, and S6).

\section{Haplotype analysis}

The pairwise LD values ( $\mathrm{D}^{\prime}$ and $\mathrm{r} 2$ ) among the studied variants in the NPY gene are provided in the supplements. Strong LD was found between variants NPY c.150G >A and NPY c.-485T >C, which are separated by $41 \mathrm{~kb}\left(\mathrm{D}^{\prime}=0.967 ; \mathrm{r} 2=0.909\right)$. However, a weak LD 
Table 2 - Analysis of the variants of the genes in the different degrees of TIMI Risk

\begin{tabular}{|c|c|c|c|c|c|c|c|}
\hline \multirow{4}{*}{ Variants (genotype) } & \multicolumn{7}{|c|}{ TIMI Risk Score } \\
\hline & \multirow{2}{*}{\multicolumn{2}{|c|}{$\begin{array}{c}\text { Low } \\
(n=77)\end{array}$}} & \multirow{2}{*}{\multicolumn{2}{|c|}{$\begin{array}{c}\text { Intermediate/High * } \\
(\mathrm{n}=144)\end{array}$}} & \multirow[b]{3}{*}{ OR } & \multirow[b]{3}{*}{$95 \%$ CI } & \multirow[b]{3}{*}{ p } \\
\hline & & & & & & & \\
\hline & $\mathbf{N}$ & $\%$ & $\mathbf{n}$ & $\%$ & & & \\
\hline \multicolumn{8}{|l|}{ NPY c.20T> C (rs16139) } \\
\hline TT & 69 & 89.61 & 140 & 97.22 & 1 & & \\
\hline $\mathrm{TC} / \mathrm{CC}$ & 8 & 10.39 & 4 & 2.78 & 0.25 & $0.06-0.81$ & 0.0261 \\
\hline \multicolumn{8}{|l|}{ NPY c.84G>A（rs5572) } \\
\hline GG & 71 & 92.21 & 136 & 94.44 & 1 & & \\
\hline AG/AA & 6 & 7.79 & 8 & 5.56 & 0.70 & $0.23-2.19$ & 0.5173 \\
\hline \multicolumn{8}{|l|}{ NPY c.150G>A（rs5573） } \\
\hline GG & 22 & 28.57 & 33 & 22.92 & 1 & & \\
\hline GA/AA & 55 & 71.43 & 111 & 77.08 & 1.35 & $0.71-2.51$ & 0.3551 \\
\hline \multicolumn{8}{|l|}{ NPY c.-485T>C (rs16147)** } \\
\hline TT & 21 & 27.63 & 37 & 26.06 & 1 & & \\
\hline $\mathrm{TC} / \mathrm{CC}$ & 55 & 72.37 & 105 & 73.94 & 1.08 & $0.57-2.02$ & 0.8020 \\
\hline \multicolumn{8}{|l|}{ NPY2R c.-1088T>C (rs6857715) } \\
\hline TT & 14 & 18.18 & 25 & 17.36 & 1 & & \\
\hline $\mathrm{TC} / \mathrm{CC}$ & 63 & 81.82 & 119 & 82.64 & 1.06 & $0.50-2.15$ & 0.5300 \\
\hline \multicolumn{8}{|l|}{ NPY2R c.-1116A> G (rs6857530) } \\
\hline AA & 20 & 25.97 & 54 & 37.50 & 1 & & \\
\hline AG/GG & 57 & 74.03 & 90 & 62.50 & 0.58 & $0.31-1.07$ & 0.0852 \\
\hline
\end{tabular}

was found between the NPY2R c.-1088C >T and NPY2R c.-1116A>G variants (Supplementary Figure S7).

\section{Discussion}

Genotyping of NPY and NPY2R polymorphisms in 221 ACS patients and 278 healthy controls indicated that the NPY c.20T $>$ C polymorphism significantly raised the risk of ACS. The NPY2R c.-1116A>G contributes to the development of the early stages of the syndrome. In addition to this, the NPY c.20T>C is associated with a protective effect in ACS severity.

NPY has been linked to hypertension, congestive heart failure, and other cardiovascular diseases due to its high sympathetic nervous system activity. ${ }^{33}$ The NPY c.20T>C variant has been linked to cardiovascular pathologies, such as accelerated and early progression of atherosclerosis, 5,6 acute myocardial infarction, and cerebrovascular disease in hypertensive patients. ${ }^{8}$ The results of the present study were similar to those reported by Masoudi-Kazemabad et al., ${ }^{9}$ which showed an association between NPY c.20T>C and coronary artery disease in an Iranian population. ${ }^{9}$ Wallerstedt et al., ${ }^{8}$ demonstrated the association of this variant with acute myocardial infarction in a Swedish hypertensive population. ${ }^{8}$ The NPY c.20T $>$ C variant was initially associated with increased cholesterol and lowdensity lipoprotein (LDL) levels, ${ }^{5}$ in obese and healthy individuals. ${ }^{6}$ In a subsequent study in Finnish women with coronary heart disease, the NPY c.20T $>$ C is associated with total cholesterol, but not with LDL. ${ }^{34}$ Further, the 
Table 3 - Analysis of the variant NPY c.84G >A with habits and biological and clinical features

\begin{tabular}{|c|c|c|c|c|c|c|c|c|}
\hline & \multicolumn{4}{|c|}{ NPY c.84G>A（rs5572） } & \multirow{3}{*}{ OR } & \multirow{2}{*}{\multicolumn{2}{|c|}{$95 \% \mathrm{CI}$}} & \multirow{3}{*}{$\mathbf{p}$} \\
\hline Variables & \multicolumn{2}{|c|}{ GG } & \multicolumn{2}{|c|}{ GA/AA } & & & & \\
\hline & $\mathbf{N}$ & $\%$ & $\mathbf{N}$ & $\%$ & & Inf & Sup & \\
\hline \multicolumn{9}{|l|}{ Onset of ACS } \\
\hline Prospective & 95 & 45.89 & 4 & 28.57 & & & & \\
\hline Premature & 112 & 54.11 & 10 & 71.43 & 2.12 & 0.69 & 7.93 & 0.2162 \\
\hline \multicolumn{9}{|l|}{ Gender } \\
\hline Male & 156 & 75.36 & 12 & 85.71 & 1.00 & & & \\
\hline Female & 51 & 24.64 & 2 & 14.29 & 0.51 & 0.08 & 1.95 & 0.3881 \\
\hline \multicolumn{9}{|l|}{ Premature } \\
\hline Male & 102 & 82.26 & 9 & 90 & & & & \\
\hline Female & 22 & 17.74 & 1 & 10 & 0.5152 & 0.03 & 2.95 & 0.539 \\
\hline \multicolumn{9}{|l|}{ Prospective } \\
\hline Male & 54 & 44.26 & 3 & 60 & 1.00 & & & \\
\hline Female & 68 & 55.74 & 2 & 40 & 0.5294 & 0.07 & 3.30 & 0.4945 \\
\hline \multicolumn{9}{|l|}{ Gender/Time } \\
\hline \multicolumn{9}{|l|}{ Male } \\
\hline Prospective & 54 & 34.62 & 3 & 25 & 1.00 & & & \\
\hline Premature & 102 & 65.38 & 9 & 75 & 1.5882 & 0.45 & 7.38 & 0.501 \\
\hline \multicolumn{9}{|l|}{ Female } \\
\hline Prospective & 41 & 80.39 & 1 & 50 & 1.00 & & & \\
\hline Premature & 10 & 19.61 & 1 & 50 & 4.1 & 0.15 & 109.92 & 0.333 \\
\hline \multicolumn{9}{|l|}{ Smoking } \\
\hline No & 150 & 72.46 & 12 & 85.71 & 1.00 & & & \\
\hline Yes & 57 & 27.54 & 2 & 14.29 & 2.27 & 0.60 & 14.29 & 0.2903 \\
\hline \multicolumn{9}{|l|}{ Diabetes } \\
\hline No & 117 & 56.52 & 9 & 64.29 & 1.00 & & & \\
\hline Yes & 90 & 43.48 & 5 & 35.71 & 1.38 & 0.46 & 4.55 & 0.5715 \\
\hline \multicolumn{9}{|l|}{ Hypertension } \\
\hline No & 45 & 21.74 & 7 & 50.00 & 1.00 & & & \\
\hline Yes & 162 & 78.26 & 7 & 50.00 & 3.57 & 1.18 & 11.11 & 0.0223 \\
\hline \multicolumn{9}{|l|}{ Dyslipidemia } \\
\hline No & 84 & 40.58 & 5 & 35.71 & 1.00 & & & \\
\hline Yes & 123 & 59.42 & 9 & 64.29 & 0.81 & 0.2427 & 2.4390 & 0.7198 \\
\hline \multicolumn{9}{|l|}{ Change in CRP } \\
\hline No & 65 & 34.76 & 6 & 46.15 & 1.00 & & & \\
\hline Yes & 122 & 65.24 & 7 & 53.85 & 0.62 & 0.20 & 2.00 & 0.4100 \\
\hline
\end{tabular}




\begin{tabular}{|c|c|c|c|c|c|c|c|c|}
\hline \multicolumn{9}{|l|}{ ALN * } \\
\hline 0 & 11 & 5.79 & 2 & 14.29 & 1.00 & & & \\
\hline$\leq 2$ & 96 & 50.53 & 8 & 57.14 & 0.46 & 0.09 & 2.43 & 0.3597 \\
\hline$>2$ & 83 & 43.68 & 4 & 28.57 & 0.26 & 0.04 & 1.62 & 0.1503 \\
\hline \multicolumn{9}{|c|}{ TROPONIN I > 0.11 ng/ml } \\
\hline No & 30 & 14.63 & 1 & 7.14 & 1.00 & & & \\
\hline Yes & 175 & 85.37 & 13 & 92.86 & 2.23 & 0.42 & 41.22 & 0.4481 \\
\hline \multicolumn{9}{|c|}{ CK-MB mass $>5.6 \mathrm{ng} / \mathrm{ml}$} \\
\hline No & 58 & 30.85 & 5 & 38.46 & 1.00 & & & \\
\hline Yes & 130 & 69.15 & 8 & 61.54 & 0.71 & 0.23 & 2.45 & 0.5688 \\
\hline \multicolumn{9}{|l|}{ EF } \\
\hline$<50 \%$ & 66 & 36.67 & 5 & 38.46 & 1.00 & & & \\
\hline$\geq 50 \%$ & 114 & 63.33 & 8 & 61.54 & 0.93 & 0.30 & 3.17 & 0.8969 \\
\hline
\end{tabular}

NPY c.20T $>C$ is associated with altered lipid metabolism ${ }^{18}$ and increased the susceptibility to type 2 diabetes mellitus (T2DM) and diabetic retinopathy in T2DM. ${ }^{35}$ Bhaskar et al., ${ }^{11}$ evaluated the NPY c.20T>C variant with hypertension and found an association. ${ }^{11}$ The variations in the associations are due to variations in allele frequencies across populations. The carrier frequency of the C allele of the NPY c.20T>C ranges from 6-15\% in Caucasian populations, but it is very low or absent in Eastern populations. ${ }^{36,3}$ The highest allele frequencies were found in the Nordic countries. Moreover, the NPY c.20T>C could originate in northern Europe and then spread to neighboring regions. ${ }^{36}$ Our results showed no association between NPY variant c.84G $>$ A and ACS, corroborating with Shah et al., ${ }^{7}$ who showed no existence of an association of this variant with the early onset of atherosclerosis in American and European populations. Regarding NPY c.150G >A, it was not associated with hypertension, corroborating Bhaskar et al., ${ }^{11}$ Studies with Korean and Chinese populations have shown that the variant c. $-485 \mathrm{~T}>\mathrm{C}$ of NPY can be considered a genetic risk factor or be involved with stroke. ${ }^{16,17}$ Likewise, Shah et al., 7 demonstrated the association of this variant with the risk of developing early atherosclerosis. Our findings indicate that the NPY $2 R$ variant c. $-1116 \mathrm{~A}>\mathrm{G}$ is associated with ACS. Although no studies corroborate our findings, the NPY2R variant c.-1116A>G has been associated with obesity in Caucasian Danes ${ }^{23}$ and with HDL-C in Japanese populations..$^{25}$
In the present study, pairwise LD values between NPY c. $20 \mathrm{~T}>\mathrm{C}$ and c.150G $>\mathrm{A}$ variants indicated that there is no strong $\mathrm{LD}$ between these markers. These findings were corroborated by a few other studies that did not report a significant LD between these markers. ${ }^{10,11}$ Further, a weak LD between the NPY c.20T $>C$ and c. $-485 T>C$ variants was demonstrated in this study, corroborating with Patel et al., ${ }^{18}$ The possible explanation for the weak LD between these markers is due to the lack of recombination between adjacent markers or low frequency of the alleles. ${ }^{3}$

The study's primary limitation is that the evaluated population was from Brazil, a country well-known for its high genetic heterogeneity. Genetic diversity studies in five Brazilian geopolitical regions revealed that European ancestry contributed the most $(77.1 \%)$, followed by African (14.3\%) and Amerindian (8.5\%) contributions. ${ }^{38}$ Pena et al. ${ }^{39}$ also showed that the European ancestry was predominant in all regions studied in Brazil, with proportions ranging from $60.6 \%$ in the Northeast to $77.7 \%$ in the South. Further, Ferreira et al., ${ }^{40}$ demonstrated that $79 \%$ of contributions to a population in the state of São Paulo came from Europeans, 14\% from Africans, and 7\% from indigenous Brazilian Amerindians. Furthermore, the Rio de Janeiro population had a predominantly European genetic influence (from 55.2 to $58.6 \%$ ), followed by African (from 31.1 to $30.3 \%$ ) and Amerindian (from 13.7 to $11.0 \%$ ) contributions. ${ }^{41}$ Further, the number of individuals studied may limit the conclusions of our results. 
Table 4 - Analysis of the variant NPY2R c.-1116A>G with habits and biological and clinical features

\begin{tabular}{|c|c|c|c|c|c|c|c|c|}
\hline & \multicolumn{4}{|c|}{ NPY2R c.-1116A> G (rs6857530) } & \multirow{3}{*}{ OR } & \multirow{2}{*}{\multicolumn{2}{|c|}{$95 \% \mathrm{CI}$}} & \multirow{3}{*}{ p } \\
\hline Variables & \multicolumn{2}{|c|}{ AA } & \multicolumn{2}{|c|}{ AG/GG } & & & & \\
\hline & $\mathbf{N}$ & $\%$ & $\mathbf{N}$ & $\%$ & & Inf & Sup & \\
\hline \multicolumn{9}{|l|}{ Onset of ACS } \\
\hline Prospective & 41 & 55.41 & 58 & 39.46 & 1.00 & & & \\
\hline Premature & 33 & 44.59 & 89 & 60.54 & 1.91 & 1.09 & 3.37 & 0.0253 \\
\hline \multicolumn{9}{|l|}{ Gender } \\
\hline Male & 53 & 71.62 & 115 & 78.23 & 1.00 & & & \\
\hline Female & 21 & 28.38 & 32 & 21.77 & 0.70 & 0.37 & 1.34 & 0.2787 \\
\hline \multicolumn{9}{|l|}{ Premature } \\
\hline Male & 30 & 78.95 & 81 & 82.65 & 1.00 & & & \\
\hline Female & 8 & 21.05 & 17 & 17.35 & 0.787 & 0.3145 & 2.1008 & 0.6172 \\
\hline \multicolumn{9}{|l|}{ Prospective } \\
\hline Male & 23 & 48.94 & 34 & 41.46 & 1.00 & & & \\
\hline Female & 24 & 51.06 & 48 & 58.54 & 1.3529 & 0.657 & 2.7931 & 0.4114 \\
\hline \multicolumn{9}{|l|}{ Gender/Time } \\
\hline \multicolumn{9}{|l|}{ Male } \\
\hline Prospective & 23 & 43.4 & 34 & 29.57 & 1.00 & & & \\
\hline Premature & 30 & 56.6 & 81 & 70.43 & 1.8265 & 0.9275 & 3.5934 & 0.0802 \\
\hline \multicolumn{9}{|l|}{ Female } \\
\hline Prospective & 18 & 85.71 & 24 & 75 & 1.00 & & & \\
\hline Premature & 3 & 14.29 & 8 & 25 & 2 & 0.4983 & 10.1178 & 0.3524 \\
\hline \multicolumn{9}{|l|}{ Smoking } \\
\hline No & 55 & 74.32 & 107 & 72.79 & 1.00 & & & \\
\hline Yes & 19 & 25.68 & 40 & 27.21 & 1.08 & 0.58 & 2.07 & 0.8077 \\
\hline \multicolumn{9}{|l|}{ Diabetes } \\
\hline No & 41 & 55.41 & 85 & 57.82 & 1.00 & & & \\
\hline Yes & 33 & 44.59 & 62 & 42.18 & 0.91 & 0.52 & 1.60 & 0.7319 \\
\hline \multicolumn{9}{|l|}{ Hypertension } \\
\hline No & 16 & 21.62 & 36 & 24.49 & 1.00 & & & \\
\hline Yes & 58 & 78.38 & 111 & 75.51 & 0.85 & 0.43 & 1.64 & 0.6354 \\
\hline \multicolumn{9}{|l|}{ Dyslipidemia } \\
\hline No & 30 & 40.54 & 59 & 40.14 & & & & \\
\hline Yes & 44 & 59.46 & 88 & 59.86 & 1.02 & 0.57 & 1.79 & 0.9539 \\
\hline \multicolumn{9}{|l|}{ Change in CRP } \\
\hline No & 24 & 34.29 & 47 & 36.15 & 1.00 & & & \\
\hline Yes & 46 & 65.71 & 83 & 63.85 & 0.92 & 0.50 & 1.69 & 0.7923 \\
\hline
\end{tabular}




\begin{tabular}{|c|c|c|c|c|c|c|c|c|}
\hline \multicolumn{9}{|l|}{ ALN * } \\
\hline 0 & 5 & 7.35 & 8 & 5.88 & 1.00 & & & \\
\hline$\leq 2$ & 35 & 51.47 & 69 & 50.74 & 1.23 & 0.38 & 4.05 & 0.7307 \\
\hline$>2$ & 28 & 41.18 & 59 & 43.38 & 1.32 & 0.39 & 4.39 & 0.6541 \\
\hline \multicolumn{9}{|c|}{ TROPONIN I > $0.11 \mathrm{ng} / \mathrm{ml}$} \\
\hline No & 13 & 58.82 & 18 & 56.62 & 1.00 & & & \\
\hline Yes & 60 & 41.18 & 128 & 43.38 & 1.54 & 0.70 & 3.33 & 0.2752 \\
\hline \multicolumn{9}{|c|}{ CK-MB mass $>5.6 \mathrm{ng} / \mathrm{ml}$} \\
\hline No & 20 & 30.30 & 43 & 31.85 & 1.00 & & & \\
\hline Yes & 46 & 69.70 & 92 & 68.15 & 0.93 & 0.49 & 1.75 & 0.8241 \\
\hline \multicolumn{9}{|l|}{ EF } \\
\hline$<50 \%$ & 26 & 40.00 & 45 & 35.16 & 1.00 & & & \\
\hline$\geq 50 \%$ & 39 & 60.00 & 83 & 64.84 & 1.23 & 0.66 & 2.27 & 0.5099 \\
\hline
\end{tabular}

\section{Conclusions}

In summary, the NPY c.20T $>C$ variant appears to contribute to the development of ACS. The NPY2R c. $-1116 A>G$ variant may contribute to the early development of ACS, and the NPY c.84G>A variant appears to contribute to the development of hypertension. In addition, the NPY c.20T $>C$ is associated with a protective effect in ACS severity. This information contributes to a better understanding of the effect of NPY and NPY2R variants in the population under study. Further research with a larger sample size is necessary to confirm our results.

\section{Acknowledgments}

We thank FIOCRUZ CNPq Proep APQ 1620 4.01/15, who funded this work.

\section{Author contributions}

Conception and design of the research: Soares $\mathrm{F}$, Werkhauser RP, Moraes CNL, Martins DBG, Montenegro SML. Acquisition of data: Soares F, Araújo RM, Carvalho VDCV, Amorim EAS, Silva LCA, Montenegro ST, Neco HVPC. Analysis and interpretation of the data: Soares F, Araújo RM, Werkhauser RP, Bhaskar LVKS, Neco HVPC, Moraes CNL, Martins DBG, Montenegro SML. Statistical analysis: Diniz GT, Tashiro T. Obtaining financing:
Montenegro SML. Writing of the manuscript: Soares F. Critical revision of the manuscript for intellectual content: Araújo RM, Werkhauser RP, Bhaskar LVKS, Carvalho VDCV, Amorim EAS, Silva LCA, Montenegro ST, Moraes CNL, Martins DBG, Montenegro SML.

\section{Potential Conflict of Interest}

No potential conflict of interest relevant to this article was reported.

\section{Sources of Funding}

This study was funded by FIOCRUZ CNPq Proep APQ 1620 4.01/15.

\section{Study Association}

This article is part of the thesis of master submitted by Fábia Carla Silva Soares, from Aggeu Magalhães Institute (FIOCRUZ/PE).

\section{Ethics approval and consent to participate}

This study was approved by the Ethics Committee of the Aggeu Magalhães Institute (FIOCRUZ/PE) under the protocol number CAAE: 03187512.2.0000.5202. All the procedures in this study were in accordance with the 1975 Helsinki Declaration, updated in 2013. Informed consent was obtained from all participants included in the study. 


\section{References}

1. Blomqvist AG, Herzog H. Y-receptor subtypes--how many more? Trends Neurosci. 1997;20(7):294-8. doi:10.1016/S0166-2236(96)01057-0.

2. Movafagh S, Hobson JP, Spiegel S, Kleinman HK, Zukowska Z. Neuropeptide $\mathrm{Y}$ induces migration, proliferation, and tube formation of endothelial cells bimodally via Y1, Y2, and Y5 receptors. FASEB J. 2006;20(11):1924-6. doi:10.1096/fj.05-4770fje.

3. Saraf R, Mahmood F, Amir R, Matyal R. Neuropeptide $Y$ is an angiogenic factor in cardiovascular regeneration. Eur J Pharmacol, 2016 Apr 5;776:64-70. doi:10.1016/j.ejphar.2016.02.033.

4. Larhammar D, Salaneck E. Molecular evolution of NPY receptor subtypes. Neuropeptides. 2004 Aug; 38(4):141-51. doi:10.1016/j. npep.2004.06.002.

5. Karvonen MK, Pesonen U, Koulu M, Niskanen L, Laakso M, Rissanen A, et al. Association of a leucine(7)-to-proline(7) polymorphism in the signal peptide of neuropeptide $\mathrm{Y}$ with high serum cholesterol and LDL cholesterol levels. Nat Med. 1998;4(12):1434-7. doi:10.1038/4027.

6. Karvonen MK, Valkonen VP, Lakka TA, Salonen R, Koulu M, Pesonen U, et al. Leucine7 to proline7 polymorphism in the preproneuropeptide $\mathrm{Y}$ is associated with the progression of carotid atherosclerosis, blood pressure and serum lipids in Finnish men. Atherosclerosis. 2001;159(1):145-51. doi:10.1016/S0021-9150(01)00468-3.

7. Shah SH, Freedman NJ, Zhang L, Crosslin DR, Stone DH, Haynes C, et al. Neuropeptide $\mathrm{Y}$ gene polymorphisms confer risk of early-onset atherosclerosis. PLoS Genet 2009;5(1):e1000318.. doi:10.1371/journal. pgen. 1000318

8. Wallerstedt SM, Skrtic S, Eriksson A-L, Ohlsson C, Hedner T Association analysis of the polymorphism T1128C in the signal peptide of neuropeptide $\mathrm{Y}$ in a Swedish hypertensive population. J Hypertens. 2004;22(7):1277-81. doi:10.1097/01.hjh.0000125415.50839.7b.

9. Masoudi-Kazemabad A, Jamialahmadi K, Moohebati M, Mojarrad M, Dehghan-Manshadi R, Forghanifard MM, et al. High frequency of Neuropeptide $Y$ Leu7Pro polymorphism in an Iranian population and its association with coronary artery disease. Gene 2012;496(1):22-7. doi:10.1016/j.gene.2012.01.002.

10. Bhaskar LVKS, Thangaraj K, Non a L, Praveen Kumar K, Pardhasaradhi $\mathrm{G}$, Singh L, et al. Neuropeptide $\mathrm{Y}$ gene functional polymorphism influences susceptibility to hypertension in Indian population. J Hum Hypertens. 2009;24(9):617-22. doi:10.1038/jhh.2009.104.

11. Bhaskar LVKS, Thangaraj K, Pardhasaradhi G, Kumar KP, Singh L, Rao VR. Neuropeptide Y gene polymorphisms are not associated with obesity in a South Indian population. Eur J Clin Nutr. 2010;64(8):868-72. doi:10.1038/ejcn.2010.74

12. Krishnan M, Thompson JM, Mitchell EA, Murphy R, McCowan LM, Shelling AN. Analysis of association of gene variants with obesity traits in New Zealand European children at 6 years of age. Mol Bio Systems. 2017;13(8):1524-33. doi:10.1039/C7MB00104E

13. Domschke K, Hohoff C, Jacob C, Maier W, Fritze J, Bandelow B, ... Deckert, J. Chromosome 4q31-34 panic disorder risk locus: Association of neuropeptide Y Y5 receptor variants. Am J Med Genet. Part B: Neuropsych Genet.2008;147(4):510-6. doi:doi.org/10.1002/ajmg.b.30629

14. Sommer WH, Lidström J, Sun H, Passer D, Eskay R, Parker SC, ... Margulies EH. Human NPY promoter variation rs16147: T> C as a moderator of prefrontal NPY gene expression and negative affect. Hum Mutat. 2010;31(8):E1594-E1608. doi: doi.org/10.1002/humu.21299

15. Zhou Z, Zhu G, Hariri AR, Enoch MA, Scott D, Sinha R, Hodgkinson CA. Genetic variation in human NPY expression affects stress response and emotion. Nature. 2008;452(7190):997. doi:doi.org/10.1038/ nature 06858

16. Kim NS, Oh SM, Ko MM, Cha MH, Kang BK, Bang OS. Association of the C-399T promoter polymorphism of neuropeptide $\mathrm{Y}$ with susceptibility to ischemic stroke. Clin Biochem. 2009;42(9):1699-704. doi: org/10.1016/j. clinbiochem.2009.07.012
17. Yu JT, Yu NN, Gao SS, Song JH, Ma T, Wang ND, ... Tan L. Neuropeptide $\mathrm{Y}$ polymorphisms and ischemic stroke in Chinese population. Clin Chim Acta. 2010;411(3-4):242-5.

18. Patel R, Dwivedi M, Mansuri MS, Ansarullah, Laddha NC, Thakker A, et al. Association of Neuropeptide-Y (NPY) and Interleukin-1beta (IL1B), genotype-phenotype correlation and plasma lipids with Type-II diabetes. PLoS One. 2016;11(10)::e0164437.. doi:10.1371/journal.pone.0164437.

19. de Luis DA, Izaola O, de la Fuente B, Primo D, Aller R. Polymorphism of neuropeptide $\mathrm{Y}$ gene rs16147 modifies the response to a hypocaloric diet on cardiovascular risk biomarkers and adipokines. J Hum Nutr Diet. 2017;30(2):159-65. doi: 10.1111/jhn.12406

20. Hirsch D, Zukowska Z. NPY and stress 30 years later: The peripheral view. Cell Mol Neurobiol. 2012;32(5):645-59. doi:10.1007/s10571-011-9793-z.

21. Ma L, Tataranni PA, Hanson RL, Infante AM, Kobes S, Bogardus C, et al. Variations in peptide $\mathrm{YY}$ and $\mathrm{Y} 2$ receptor genes are associated with severe obesity in Pima Indian men. Diabetes. 2005;54(5):1598-602. doi:10.2337/ diabetes.54.5.1598.

22. Siddiq A, Gueorguiev M, Samson C, Hercberg S, Heude B, Levy-Marchal C, et al. Single nucleotide polymorphisms in the neuropeptide Y2 receptor (NPY2R) gene and association with severe obesity in French white subjects. Diabetologia. 2007;50(3):574-84. doi:10.1007/s00125006-0555-2.

23. Torekov SS, Larsen LH, Andersen G, Albrechtsen A, Glümer C, BorchJohnsen $\mathrm{K}$, et al. Variants in the $5^{\prime}$ region of the neuropeptide $\mathrm{Y}$ receptor Y2 gene (NPY2R) are associated with obesity in 5,971 white subjects. Diabetologia. 2006;49(11):2653-8. doi:10.1007/s00125-006-0425-y.

24. Treutlein J, Strohmaier J, Frank J, Witt SH, Rietschel L, Forstner AJ, et al. Association between neuropeptide $\mathrm{Y}$ receptor $\mathrm{Y} 2$ promoter variant rs6857715 and major depressive disorder. Psychiatr Genet. 2017;27(1):347. doi: 10.1097/YPG.0000000000000149.

25. Takiguchi E, Fukano C, Kimura Y, Tanaka M, Tanida K, Kaji H. Variation in the $5^{\prime}$-flanking region of the neuropeptide $\mathrm{Y} 2$ receptor gene and metabolic parameters. Metabolism. 2010;59(1):1591-6. doi:10.1016/j. metabol.2010.02.014.

26. Han C, Wang XA, Fiscus RR, Gu J, McDonald JK. Changes in cardiac neuropeptide $Y$ after experimental myocardial infarction in rat. Neurosci Lett. 1989;104(1-2):141-6.

27. Cuculi F, Herring N, De Caterina AR, Banning AP, Prendergast BD, Forfar JC, et al. Relationship of plasma neuropeptide $\mathrm{Y}$ with angiographic, electrocardiographic and coronary physiology indices of reperfusion during ST elevation myocardial infarction. Heart 2013;99(10):1198-203. doi:10.1136/heartjnl-2012-303443.

28. Hulting J, Sollevi A, Ullman B, Franco-Cereceda A, Lundberg JM. Plasma neuropeptide $\mathrm{Y}$ on admission to a coronary care unit: raised levels in patients with left heart failure. Cardiovasc Res. 1990;24(2):102-8. doi:10.1093/cvrese/24.2.102.

29. Ullman B, Hulting J, Lundberg JM. Prognostic value of plasma neuropeptide- $Y$ in coronary care unit patients with and without acute myocardial infarction. Eur Heart J. 1994;15(4):454-61.

30. Antman EM, Cohen M, Bernink PJ, McCabe CH, Horacek T, Papuchis $\mathrm{G}$, et al. The TIMI risk score for unstable angina/non-ST elevation MI: a method for prognostication and therapeutic decision making. JAMA, 2000;284(7):835-42. doi:10.1001/jama.284.7.835

31. Morrow DA, Antman EM, Charlesworth A, Cairns R, Murphy SA, de Lemos JA, et al.TIMI risk score for ST-elevation myocardial infarction: a convenient, bedside, clinical score for risk assessment at presentation: an intravenous nPA for treatment of infarcting myocardium early II trial substudy. Circulation, 2000;102(17):2031-7.

32. Bhaskar LVKS, Thangaraj K, Shah AM, Pardhasaradhi G, Praveen Kumar K, Reddy AG, et al. Allelic variation in the NPY gene in 14 Indian populations. J Hum Genet. 2007;52(7):592-8. doi:10.1007/s10038007-0158-x. 
33. McDermott BJ, Bell D. NPY and cardiac diseases. Curr Top Med Chem. 2007;7(7):1692-703. doi:10.2174/156802607782340939.

34. Erkkilä A T, Lindi V, Lehto S, LaaksoM,Uusitupa M I. Association of leucine 7 to proline 7 polymorphism in the preproneuropeptide $Y$ with serum lipids in patients with coronary heart disease. Mol Genet Metabol.2002; 75(3), 260-4. doi:doi.org/10.1006/mgme.2002.3302

35. Niskanen L, Karvonen MK, Valve R, Koulu M, Pesonen U, Mercuri M, et al. Leucine 7 to proline 7 polymorphism in the neuropeptide $\mathrm{Y}$ gene is associated with enhanced carotid atherosclerosis in elderly patients with type 2 diabetes and control subjects. J Clin Endocrinol Metab. 2000;85(6):2266-9. doi:10.1210/jc.85.6.2266.

36. Ding B. Distribution of the NPY 1128C allele frequency in different populations. J Neural Transm. 2003;110(11):1199-204. doi:10.1007/ s00702-003-0034-6.

37. Jia C, Liu Z, Liu T, Ning Y. The T1128C polymorphism of neuropeptide Y gene in a Chinese population. Arch Med Res. 2005;36(2):175-7. doi:10.1016/j.arcmed.2004.12.005.
38. Lins TC, Vieira RG, Abreu BS, Grattapaglia D, Pereira RW. Genetic composition of Brazilian population samples based on a set of twentyeight ancestry informative SNPs. Am J Hum Biol. 2010;22(21):187-92. doi:10.1002/ajhb.20976.

39. Pena SD, Di Pietro G, Fuchshuber-Moraes M, Genro JP, Hutz MH, Kehdy FDSG, de Moraes MEA. The genomic ancestry of individuals from different geographical regions of Brazil is more uniform than expected. PloS One. 2011;6(2):e17063. doi:10.1371/journal.pone.0017063.

40. Ferreira, L. B., Mendes, C. T., Wiezel, C. E. V., Luizon, M. R., \& Simões, A. L. (2006). Genomic ancestry of a sample population from the state of Sao Paulo, Brazil. Am J Hum Biol. 2006;18:702-5. doi: doi.org/10.1002/ ajhb.20474

41. Manta FSN, Pereira R, Vianna R, de Araújo ARB, Gitaí DLG, da Silva DA, de Carvalho EF. Revisiting the genetic ancestry of Brazilians using autosomal AIM-Indels. PloS One. 2013;8(9):e75145. doi:10.1371/ journal.pone.0075145

\section{*Supplemental Materials}

To access supplementary table 1 , click here. To access supplementary table 2 , click here. To access supplementary table 3, click here. To access supplementary table 4 , click here. To access supplementary table 5 , click here. To access supplementary table 6 , click here. To access supplementary table 7 , click here. 